\title{
A administração no crepúsculo do reino: registros de Saint-Hilaire
}

\author{
Marcos Lopez Rego ${ }^{1}$ \\ Hélio Reis Arthur Irigaray 2 \\ 1 Pontifícia Universidade Católica do Rio de Janeiro / IAG Escola de Negócios, Rio de Janeiro / RJ - Brasil \\ 2 Fundação Getulio Vargas / Escola Brasileira de Administração Pública e de Empresas, Rio de Janeiro / RJ - Brasil
}

O objetivo deste ensaio é analisar a estrutura e a operação da gestão pública no Reino Unido de Portugal, Brasil e Algarves, relacionadas à indústria extrativista de diamantes por meio das obras de Saint-Hilaire, botânico e naturalista francês, que visitou e percorreu o Brasil no século XIX, em viagem realizada em 1817. O autor descreveu aspectos ligados à estrutura organizacional, aos processos da operação de extração de diamantes, aos métodos de gestão pública, de recursos humanos, financeira e contratos no distrito dos diamantes. A análise de seus relatos revelou o alto grau de controle, bem como as condições de trabalho dos escravos e a rígida estratificação social do Brasil Império, com intensa utilização de mão de obra escrava, por meio do que se chamava à época de aluguel. Conclui-se que o autor fez extenso relato da operação, com inestimável contribuição para os estudos dos primórdios do Estado brasileiro.

Palavras-chave: história administrativa; indústria extrativista; gestão do ciclo dos diamantes.

\section{Administración en el crepúsculo del reino: los registros de Saint-Hilaire}

El objetivo de este ensayo fue analizar la estructura y la operación de la gestión pública del Reino Unido de Portugal, Brasil y Algarves, relacionadas con la industria de extracción de diamantes a través de las obras de Saint-Hilaire, botánico y naturalista francés, que recorrió Brasil, en un viaje que realizado en 1817. El autor describió en detalles aspectos relacionados con la estructura organizacional, los procesos de la operación de extracción, los métodos de gestión pública, de recursos humanos, financiera y de contratos. El análisis de sus relatos reveló el alto grado de control, así como el uso intensivo del trabajo esclavo, a través de la subcontratación de recursos humanos, las condiciones de trabajo de los esclavos y la rígida estratificación social del reino. Se concluye que el autor presentó una detallada descripción de la operación lo que constituye una invaluable contribución a los estudios de los inicios del Estado brasileño.

Palabras clave: historia administrativa; industria extractiva; gestión del ciclo del diamante.

\section{Administration in the twilight of the kingdom: Saint-Hilaire's records}

This essay aims to analyze the structure and operation of the public management of the United Kingdom of Portugal, Brazil, and the Algarves, related to the diamond extraction industry through the texts of Saint-Hilaire, French botanist and naturalist. Saint-Hilaire visited and toured Brazil in 1817 in a journey throughout the country's interior offering detailed information on Brazil's organizational structure, operations management structure, the public management processes, and the management of human resources, finances, and contracts. The analysis of SaintHilaire's reports revealed a high degree of control, the slaves' work conditions, and the rigid social stratification of Brazil in the early 19th century. The essay concludes that Saint-Hilaire presented a deep and detailed description of the diamond extraction operation, offering a valuable contribution to the studies of the beginning of Brazil as an independent nation.

Keywords: administrative history; extractive industry; diamond cycle management. 


\section{INTRODUÇÃO}

O método de pesquisa histórico objetiva sistematizar, identificar, coletar, organizar e avaliar criticamente fontes documentais que têm relação com ocorrências do passado (Samara \& Tupy, 2017).

No Brasil, as pesquisas historiográficas em administração têm se debruçado sobre história empresarial (Costa, Barros \& Martins, 2010; Curado, 2001; Vizeu, 2010); discussões relacionadas às fontes da pesquisa histórica (Coraiola, 2012; Barros, 2016), ao cotidiano e à história em si (Barros \& Carrieri, 2013); formação do campo do ensino de administração (Bertero, Barros \& Alcadipani, 2018; Vizeu, 2018; Wanderley, 2015, 2016); contribuições e desafios do método de história comparada (Amorim-Neto \& Rodrigues, 2016). Esses estudos têm sido construídos sobre histórias orais (Colomby, Peres, Lopes \& Costa, 2016; Joaquim \& Carrieri, 2018) e registros como cartas, livros, relatórios, diários, pinturas, esculturas, fotografias, filmes, mitos, lendas, falas, espaços (Costa \& Silva, 2019) e depoimentos de viajantes estrangeiros no século XIX (Kuri, 2003), que é o caso deste trabalho, construído sobre os relatos de Saint-Hilaire.

O campo de estudos históricos da administração pública brasileira é escasso, como afirmado por Costa e Costa (2016). Quanto aos exames oriundos da produção de Saint-Hilaire, são inexistentes. Segundo Kuri (2003), "Saint-Hilaire é, na verdade, um desconhecido entre nós. Poucos detalhes de sua vida e sua obra foram estudados. Na França atual, ele é um personagem esquecido, o que não aconteceu em sua época quando ocupou posição de prestígio no meio científico parisiense e francês".

O botânico e naturalista francês realizou diversas viagens pelo Brasil, entre 1816 e 1822, as quais resultaram em 19 obras sobre ciências naturais, religiosidade, vida social, arquitetura, mobilidade, legislação e política, mas esses relatos têm sido negligenciados como fonte de análises do Brasil imperial (Kuri, 2003). É essa lacuna que nos propomos a preencher neste estudo, cuja pergunta de investigação é: que características da estrutura, da gestão e da operação do distrito dos diamantes são evidenciadas por Saint-Hilaire?

Para responder a ela, analisamos o livro Viagem pelo distrito dos diamantes e litoral do Brasil (Saint-Hilaire, 1974), no qual são relatadas as expedições realizadas entre 1816 e 1817. Mantivemos em mente que as fontes documentais não falam por si tampouco são imóveis depositórios de fatos ocorridos no passado (Costa \& Silva, 2019). Por essa razão, metodologicamente, valemo-nos da análise do discurso (Orlandi, 1990).

Este trabalho é relevante "dado que o estudo da administração jamais ocupou um lugar de destaque na historiografia brasileira" (Cabral, 2011), ainda que textos tenham sido produzidos dentro do que seria demarcado pejorativamente como história administrativa (Cabral \& Camargo, 2010). De fato, a análise de fontes e arquivos históricos pode contribuir para o entendimento dos fenômenos organizacionais e sua articulação com o social e o político (Costa \& Silva, 2019), uma vez que as organizações instrumentalizam estrategicamente seu passado por meio da criação e da gestão de seus acervos e arquivos documentais (Barros, 2016). No caso em pauta, há de considerar a escassez de informações, pois todo o acervo da intendência dos diamantes se perdeu num incêndio do prédio sede, o qual futuramente abrigaria a prefeitura de Diamantina (Furtado, 1996).

Este estudo está delimitado no primeiro dos 7 períodos propostos por Costa (2010), denominado "etapa da construção do Estado nacional". Essa periodização teve como objetivo propor uma alternativa à categorização anterior, que encarava a história da administração pública brasileira em 3 fases: patrimonialista, burocrática e gerencial (Bresser-Pereira, 2001). 
Este artigo está estruturado em 5 seções, além desta Introdução. Na próxima, apresentamos o contexto teórico, seguido da fonte histórica per se - no caso, o texto de Saint-Hilaire (1974) -, bem como os acontecimentos acerca do ocorrido. A terceira seção é dedicada às notas metodológicas. A quarta trata da operação histórica, isto é, o processo crítico pelo qual foi submetido o livro. Por fim, na quinta e última, apresentamos nossas reflexões, análises e propostas para futuras pesquisas.

\section{CONTEXTUALIZAÇOES: TEORIA E DOCUMENTO}

\subsection{Contextualização Histórica da Gestão Pública Brasileira}

As pesquisas e as publicações sobre a história da administração pública brasileira tem um marco inicial em Fleiuss, com o lançamento, em 1926, da História administrativa do Brasil. Na década de 1950, o Departamento Administrativo do Serviço Público (Dasp) iniciou a publicação de uma coletânea também denominada História administrativa do Brasil. Prevista em 40 volumes, ela foi interrompida em 1994, quando restavam apenas 3 a serem publicados (Ribeiro, 2009). Segundo Cabral (2011), questões de pesquisa relativas à história da administração no Brasil foram tratadas "apenas tangencialmente" pelos 2 principais autores de estudos sobre a formação do povo brasileiro, Caio Prado Junior e Sérgio Buarque de Holanda - respectivamente, nas décadas de 1930 e 1950.

Algumas leituras simplificadoras do tema afirmam que o Estado brasileiro só teria começado com a tomada de poder por Vargas em 1930 (Costa, 2010; Roncaglio, 2012). Todavia, neste estudo, partimos do pressuposto de que a história do Estado brasileiro tem antecedentes na Colônia e de que seu ponto inaugural é a chegada da família real, em 1808 (Costa, 2010; Costa \& Costa, 2018; Couto, 2010).

Nessa época, já existia no Brasil uma administração colonial a cargo de vice-reis, com um aparelhamento deficiente. A estrutura de gestão pública vigente era dividida em 4 segmentos, subordinados ao Conselho Ultramarino: instituições metropolitanas, administração central, administração regional e administração local. O conselho, por sua vez, se encontrava subordinado ao secretário de Estado dos Negócios da Marinha e Territórios Ultramarinos (Costa, 2010).

Do ponto de vista da organização territorial, o Brasil estava dividido em capitanias, cujos territórios eram subdivididos em comarcas, as quais eram compostas por termos sediados nas cidades ou vilas. Os termos eram constituídos de freguesias, que correspondiam às paróquias da circunscrição eclesiástica (Cabral \& Camargo, 2010).

Em 1808, com a transferência da corte para o Brasil, foram criadas as condições para o crescimento da burguesia brasileira, ainda que tudo tenha acontecido sem planejamento ou organização. Não existem registros de quantas pessoas vieram às pressas de Portugal. Logo após a chegada, foram criados órgãos de governo, e em 1816 o Brasil já fora elevado à condição de Reino Unido a Portugal e Algarves (Costa, 2010; Couto, 2010).

\subsection{Documento em Questão: Viagem pelo Distrito dos Diamantes}

Nessa obra, publicada originalmente em dois volumes, na França, em 1833, Saint-Hilaire descreve detalhadamente a estrutura de gestão do Reino Unido de Portugal, Brasil e Algarves (1815-1822). Este trabalho, contudo, se limita aos capítulos dedicados à viagem pelo distrito dos diamantes, em 1817. 
Auguste François Cesar Prouvençal de Saint-Hilaire, francês de família rica de Orleáns, estudou botânica no Museu de História Natural e na faculdade de Medicina de Paris. Em 1816, integrou a delegação do Duque de Luxemburgo, embaixador extraordinário da França que partia para uma missão diplomática junto à corte portuguesa. Entusiasta e curioso diante da variedade e da exuberância da natureza brasileira, Saint-Hilaire permaneceu por 6 anos no Brasil, baseado no Rio de Janeiro, de onde partiu para inúmeras viagens pelo território brasileiro. A organização e a publicação de sua obra, projeto que levou quase 30 anos para concluir, obedeceu à cronologia das diferentes expedições (Sodré, 2010). Por décadas, ele foi publicando trechos dos seus relatos no Les Nouvelles Annales des Voyages (Kury, 2003). Mesmo antes de sua expedição ao Brasil, já havia escrito sobre as relações da botânica com a sociedade, respondendo a críticas de que a botânica seria apenas uma "ciência de palavras", com suas aplicações na medicina e na agricultura (Kury, 2003).

Após meses de pesquisas botânicas no Rio de Janeiro, realizou viagem experimental até Ubá, fronteira indígena situada a 30 léguas do litoral. Segundo Sodré, o relato dessa primeira viagem já apresentava os traços que caracterizavam o autor, que não se limitou a narrativas de botânica: "Suas descrições penetram também o campo da geografia humana. Saint-Hilaire se interessa pelas formas e processos de ocupação e de exploração das terras, pela administração civil e eclesiástica, pelo léxico espacial e pelos topônimos, pelas produções agrícolas, pelo comércio, arquitetura, demografia e pelos costumes das diferentes populações" (Sodré, 2010).

Ele permaneceu no Brasil em missão oficial do Museu de História Natural da França, viagem autorizada pelo Ministro do Interior, na qualidade de viajante naturalista, com remuneração anual de 3 mil francos, logo aumentada para 6 mil (Kury, 2003). Ainda que fosse um naturalista, Saint-Hilaire não se limitou a descrever fauna e flora. Seus relatos descreveram detalhadamente o surgimento, o crescimento e a decadência de lugares, as vidas de indivíduos e famílias de diferentes condições sociais e cor de pele, seus costumes, trajes e hábitos alimentares, bem como aspectos econômicos, gerenciais e sociais da época.

Saint-Hilaire retrata éticas legais, práticas religiosas, processos de trabalho e produção. Ele também investiga problemas e perspectivas da indústria do comércio e das comunicações. Durante os 6 anos que passou no Brasil, o Museu de História Natural documentava periodicamente os progressos da jornada, na publicação Instruction pour les voyageurs, que informava sobre todos os viajantes franceses em missão (Kury, 2003).

Apesar de sua origem, a narrativa não é construída sob um olhar eurocêntrico. $\mathrm{O}$ autor se revela um estudioso instigado pelo real interesse e afeição aos seus objetos de estudo, o que nos instigou a conduzir esta análise. Segundo Kury (2003), Saint-Hilaire seria a personificação de um novo perfil de viajante naturalista idealizado no meio científico francês: pesquisa in loco, especialização, capacidade analítica e publicação dos resultados obtidos sob uma óptica integradora.

Quanto à obra em estudo, foi o segundo volume da série de 8 títulos publicados após seu regresso para a França. Na época da publicação, em 1833, o Brasil deixara a condição de Reino Unido, com a proclamação da independência, seguido do governo de Pedro I, sua renúncia e instituição do período regencial. Ao fim da obra, Saint-Hillaire apresenta um "resumo histórico" das transformações políticas ocorridas entre a sua viagem e a publicação do livro. Vivia-se a Regência Trina provisória, segundo ele, "formada por homens pouco capazes, porém moderados". Ao fim, revela a preocupação com os destinos do Brasil, ao relembrar que encontrara um país governado por Dom João VI, o qual era no Rio de Janeiro "o soberano de uma multidão de pequenos estados distintos. Havia um país chamado Brasil, mas absolutamente não havia brasileiros" (Saint-Hilaire, 1974). 


\section{NOTAS METODOLÓGICAS}

As fontes para os estudos sobre história da administração pública são repertórios de leis a respeito da organização governamental brasileira. Já falas do trono e mensagens presidenciais, relatórios do Tribunal de Contas da União, estatísticas, arquivos pessoais e histórias de vida são fontes biográficas nas quais estão incluídos os diários e as correspondências (Costa \& Costa, 2016).

Neste trabalho, corroborando com Costa e Silva (2019), entendemos que um documento deve ser visto como uma narrativa dinâmica e construída socialmente, o que nos demandou assumir uma atuação crítica e reflexiva de (re)conhecimento do texto de Saint-Hilaire, suas implicações em nossa escolha metodológica. Optou-se por trabalhar com a edição de 1974, com novo prefácio e notas de rodapé que não constavam na primeira edição em língua portuguesa, de 1941.

Neste trabalho, os valores monetários são apresentados na moeda da época, o real, e seus múltiplos, preservando-se sua forma de notação. Assim, a notação $\$ 001$ equivale a um real, $1 \$ 000$ equivale a mil réis (mil reais) e 1.000\$000 equivale a um conto de réis (um milhão de reais). Foi mantida a grafia do texto traduzido (1974), o qual, por exemplo, utilizava Tijuco, em vez de Tejuco, para denominar a localidade sede do distrito dos diamantes, que futuramente seria a cidade de Diamantina. Apenas por coerência histórica, foi mantido o vocábulo "aluguel" nas referências à mão de obra escrava.

A interpretação dos dados, feita pela análise do discurso, partiu do pressuposto de que o discursivo pode ser definido como um processo social cujas relações são historicamente modalizadas pela formação social em que se dá, ideologicamente constituída (Orlandi, 1990).

\section{0 CREPÚSCULO DO REINO NO DISTRITO DOS DIAMANTES}

\subsection{Ciclo dos Diamantes no Brasil}

Existem diferentes versões sobre o início do ciclo dos diamantes, pois os próprios partícipes do acontecimento trataram de cercá-lo de mistérios e mal-entendidos (Furtado, 1999). Saint-Hilaire (1974) afirma que Bernardo Fonseca Lobo teria sido o primeiro a descobrir diamantes no Serro Frio, em data incerta, e que em 1729 esse fato já era conhecido pela corte portuguesa.

Ainda em sua narrativa, em1730, os diamantes foram declarados de propriedade real, por meio de decreto. A busca e a exploração eram permitidas, desde que autorizadas pelo governo e de acordo com as regras estabelecidas: cada escravo empregado nessa atividade deveria gerar o pagamento de uma capitação e era proibida a exportação de diamantes em navios que não pertencessem a Portugal, sendo que o frete de transporte de cada pedra equivalia a $1 \%$ de seu valor, entre outras determinações.

Capitação foi um processo de cobrança de direitos régios que sofreu muitas contestações, tendo sido aprovado em 1731 e que passou a ser efetivamente cobrado a partir do ano seguinte (Magalhães, 2009). Ele foi instituído com duplo objetivo, pois, além de gerar recursos para a coroa, apresentava o argumento de "evitar a ociosidade dos negros forros e dos vadios em geral" (Razente, 2016). Em pouco tempo, a capitação se tornou impopular e questionada, já que incidia sem considerar eventuais lucros ou prejuízos inerentes ao setor extrativista, do ouro ou de diamantes. Foi implantada inicialmente apenas na Demarcação Diamantina ("distrito dos diamantes"), tendo sido ampliada para as capitanias de Minas Gerais e São Paulo em 1735 (Razente, 2016). 
De acordo com Svizzero (2006), após a descoberta inicial no arraial do Tijuco, os diamantes foram sendo encontrados em outros sítios de Minas Gerais e nos estados de Goiás, Mato Grosso, Mato Grosso do Sul, Bahia, Paraná, São Paulo, Piauí, Pará, Rondônia, Roraima e Amapá. O Brasil perdurou como maior produtor mundial até 1867, quando foi suplantado pela África do Sul.

A rigor, não há como estimar as reais quantidades de diamantes encontradas nas primeiras décadas de produção brasileira, graças ao intenso contrabando e garimpagem às escondidas (Svizzero, 2006), situação minimizada a partir das mudanças introduzidas pelo Marquês de Pombal.

$\mathrm{Na}$ sistemática inicial do Reino português, arrendatários extraíam os diamantes e remuneravam a coroa por meio de impostos. Tal prática, além de injusta, já que as receitas não eram proporcionais ao trabalho despendido, fez o preço dos diamantes cair nos mercados europeus, o que indica que o contrabando representava parcela significativa da produção. De acordo com Saint-Hilaire (1974), em menos de uma década os preços internacionais tiveram $75 \%$ de queda por conta do excesso de oferta, majoritariamente por contrabando, ou seja, a coroa não recebia os devidos impostos.

O distrito dos diamantes apresentava a estrutura moldada pelas mudanças realizadas por Marquês de Pombal entre 1750 e 1777, período caracterizado pelas reformas pombalinas. Sebastião José de Carvalho e Melo, o Marquês de Pombal, após 2 períodos como diplomata na Inglaterra e na Áustria, estudou o papel de Portugal na Europa, apresentando diagnósticos e propostas de mudança (Carvalho, 2003). Pombal constatou o atraso e o descompasso de Portugal ante outros países da Europa e registrou as percepções dos vizinhos acerca de seu país: ignorância, fanatismo e indolência.

A ascensão de Marquês de Pombal, que modernizou e alterou profundamente a estrutura de governo e da sociedade portuguesa, logo se fez presente no lucrativo mercado de diamantes. Articulado e estrategista, Pombal mudou totalmente o sistema de gestão quando decidiu que o próprio governo exploraria, por conta própria, as terras de diamantes. Com isso, segundo Saint-Hilaire (1974), "o distrito dos diamantes ficou como que isolado do resto do universo; situado em um país governado por um poder absoluto". Em seu texto, fica patente que esse distrito foi submetido a um despotismo ainda mais absoluto. Os laços sociais foram rompidos, ou pelo menos enfraquecidos; tudo foi sacrificado ao desejo de assegurar à coroa a propriedade exclusiva dos diamantes, conforme determinado pelo Alvará de 12 de julho de 1771, que extinguiu o sistema de contratos e estabeleceu o monopólio real da extração e da comercialização dos diamantes (Cabral \& Camargo, 2010).

Competia ao próprio Marquês de Pombal a supervisão do trabalho, o que confirma a importância estratégica dos recursos para a coroa. A modernização do Estado português e o afastamento da influência inglesa eram as estratégias determinantes nas decisões de Pombal, cuja política em relação ao Brasil apresentava 3 elementos centrais: defesa do território, expansão econômica e fortalecimento do poder central. Esses fatores se expressaram, com nitidez, na assinalada diretriz geopolítica pombalina, cujo objetivo era efetuar a conquista e a ocupação das regiões interioranas (Russel-Wood, 1998).

Esse controle foi detalhado por Saint-Hilaire, que detalhou o isolamento e o despotismo no distrito dos diamantes, além, especificamente, da relação entre contrabandistas, governo e produção de diamantes. Segundo ele, na tentativa de frear o contrabando de pedras, foram promulgadas leis centralizadoras, que passaram a reger a vida do local.

De fato, o Estado estabelecia e mantinha o controle na colônia por meio de um corpo de administradores e burocratas, escolhidos segundo perfis comportamentais definidos (RusselWood, 1998). Assim, ao mesmo tempo que a descentralização administrativa era estimulada pelo 
reino, cada capitania era objeto de controle e acompanhamento. Nelas, o espaço para autonomia de administradores e poderes locais "tinha reduzidas chances de vir a colidir com os interesses e as diretrizes reinóis" (Russel-Wood, 1998). Desse modo, a capacidade de negociação com interesses e populações locais se revela um fator determinante do sucesso da expansão dos negócios de Portugal nas colônias ultramarinas. Nas palavras de Saint-Hilaire, "os governantes e agentes não podiam manter-se isolados do ambiente que os rodeava, nem eram imunes às pressões” (1974). A rigor, em vez de serem encaradas como uma indicação de fraqueza humana ou como minando a autoridade do soberano e a eficiente administração do império, foram precisamente essas qualidades que permitiram que os portugueses enfrentassem adversidades avassaladoras por meio de uma acomodação seletiva às particularidades de um império caracterizado pela diversidade cultural e étnica (Russel-Wood, 1998).

Portugal entrou no século XIX com aparente prosperidade econômica, derivada dos recursos extraídos das colônias, mas em crise política, em função dos questionamentos do legado de Marquês de Pombal (Carvalho, 2003). Os diamantes seguiram como uma riqueza desperdiçada por um Portugal sem infraestrutura mercantil e sem domínio dos canais de comercialização; com uma burguesia forte; com capitais, técnicas, instrução, horizonte de longo prazo e um mínimo de liberdade. A sociedade portuguesa não se beneficiava disso, e o governo continuava perplexo e desorientado com a gestão dos diamantes (Rabello, 1997). Nesse cenário, incluíam-se os judeus marranos, expulsos de Portugal pela intolerância religiosa, os quais foram se abrigar em Amsterdã. Tratava-se de judeus de origem portuguesa, aqueles que detinham o conhecimento das técnicas e do ofício da lapidação. Com isso, Portugal se conformou em atuar como "mero fornecedor de pedras brutas, pois nem lapidários habilitados possuía" (Rabello, 1997).

\subsection{A Estrutura de Governança e as Funções Administrativas}

Com a instalação da Família Real no Rio de Janeiro, a cidade se tornou a capital do Império português em toda a sua extensão, incluindo colônias na África e na Ásia. A cerimônia de coroamento e aclamação de Dom João VI, em fevereiro de 1818, quase 2 anos após o falecimento de sua mãe, Dona Maria I, foi um acontecimento único na história: um soberano europeu que falece e um príncipe que sobe ao trono e é aclamado rei num antigo domínio ultramarino.

Logo após a chegada da Família Real, foram criadas mais de 20 organizações no Brasil, entre escolas, museus, órgãos públicos, academias reais e, em 5 de setembro de 1808, a diretoria e administração da Extração Diamantina, com as mesmas jurisdições da repartição antes localizada em Lisboa. Em 1812, com limitada qualidade técnica, foi instalada, no Rio de Janeiro, a Fábrica de Lapidar Diamantes, e em 14 de setembro de 1816 foi assinado um decreto destinado a aprimorar os trabalhos na Intendência dos Diamantes (Couto, 2010).

Saint-Hilaire visitou a sede da intendência, localizada no Arraial do Tijuco, atual Diamantina, o que era um privilégio, pois o distrito dos diamantes era fechado não somente aos estrangeiros, mas ainda aos nacionais, formando um estado à parte no meio do vasto Império do Brasil (Saint-Hilaire, 1974).

Nessa ocasião, o francês detalhou a estrutura de gestão do distrito de diamantes (Quadro 1), com a remuneração mensal de quase todos os envolvidos, ainda que ao longo do texto tenha utilizado e mencionado denominações distintas para as moedas do Brasil, como réis, mil-réis, contos de réis, cruzados, patacas e vinténs. Além disso, também se utiliza dos francos franceses em parte do texto. A 
fim de uniformizarmos a remuneração, em réis, valemo-nos de Costa e Marcondes (2016), que tratam da moeda no Brasil Colônia e Império. Ao descrever o custo dos principais gêneros alimentícios no arraial do Tijuco, Saint-Hilaire apresenta os valores tanto na moeda brasileira quanto na francesa, permitindo que fosse calculado um fator de conversão, utilizado neste estudo.

\section{QUADRO 1 ESTRUTURA DE GESTÃO DO DISTRITO DOS DIAMANTES}

\begin{tabular}{|c|c|c|c|c|}
\hline N. & Nome do cargo & Função & Remuneração & Quantidade \\
\hline 1 & $\begin{array}{l}\text { Intendente-geral das } \\
\text { minas }\end{array}$ & $\begin{array}{c}\text { Alvará do regimento: } \\
\text { 2/8/1771. São listadas } 20 \\
\text { atribuições do cargo, sendo } \\
\text { que ele tinha a chave do } \\
\text { cofre. }\end{array}$ & $\begin{array}{c}3.200 \$ 000+800 \$ 000 \\
\text { para despesas de viagens. }\end{array}$ & $\begin{array}{l}\text { Um. Também } \\
\text { costumava ser } \\
\text { chamado de } \\
\text { intendente dos } \\
\text { diamantes. }\end{array}$ \\
\hline 2 & $\begin{array}{l}\text { Ouvidor (fiscal dos } \\
\text { diamantes) }\end{array}$ & $\begin{array}{l}\text { Alvará do regimento: } \\
\text { 23/5/1772 } \\
\text { Função judicial. }\end{array}$ & $2.000 \$ 000$ & Um \\
\hline 3 & $\begin{array}{l}\text { Oficiais da administração } \\
\text { (caixas administradores) }\end{array}$ & $\begin{array}{l}\text { Alvará do regimento: } \\
\text { 2/8/1771, com } 10 \\
\text { atribuições. }\end{array}$ & $\mathrm{Nl}^{*}$ & $\mathrm{NI}$ \\
\hline 4 & Tesoureiro & $\begin{array}{l}\text { Guarda de valores, sendo } \\
\text { que o primeiro tesoureiro tem } \\
\text { uma das chaves do cofre. }\end{array}$ & $800 \$ 000$ & $\begin{array}{c}\text { Dois, sendo o } \\
\text { segundo também } \\
\text { "administrador geral". }\end{array}$ \\
\hline 5 & $\begin{array}{l}\text { Guarda-livros (escrivão } \\
\text { da intendência) }\end{array}$ & $\begin{array}{c}\text { Alvará do regimento: } \\
\text { 2/8/1771, com } 2 \text { atribuições. } \\
0 \text { primeiro guarda-livros tem } \\
\text { a chave do cofre. }\end{array}$ & $1.040 \$ 000$ & \\
\hline 6 & Comissários & Escrivães & $320 \$ 000$ & Sete (em 1817) \\
\hline 7 & $\begin{array}{l}\text { Administrador-geral } \\
\text { (inspetor-geral) }\end{array}$ & $\begin{array}{l}\text { Direção e vigilância da } \\
\text { extração dos diamantes. }\end{array}$ & $\begin{array}{l}\text { Em 1817, o cargo havia } \\
\text { sido suprimido, e suas } \\
\text { atribuições, passadas para } \\
\text { o } 2^{\circ} \text { tesoureiro. }\end{array}$ & Nenhum \\
\hline
\end{tabular}

* NI: Não informado

Fonte: Baseado em Saint-Hilaire (1974); Salgado (1990) e Cabral (2010).

Assumimos, baseados nas conversões de preços de gêneros alimentícios à venda no Tijuco, descritas por Saint-Hilaire (1974), que um franco francês equivalia a 160 réis. Foram identificadas algumas divergências de nomes entre Saint-Hilaire e os cargos descritos por Salgado (1990), sendo que estes se encontram entre parênteses, na coluna "Nome do cargo". Note-se que os valores das remunerações são 
apresentados somente por Saint-Hilaire, que também descreve as principais funções e a quantidade de pessoas investida em cada cargo.

Saint-Hilaire (1974), reiteradamente, destacou a concentração de poder do intendente-geral. Era um poder quase absoluto, pois regulamentava, à sua discrição, todos os aspectos do trabalho nas minas, autorizava ou impedia a entrada e a saída de pessoas, com força militar à disposição para implementar as medidas que julgasse convenientes para atacar o contrabando e a evasão fiscal.

A gestão das pedras era fundamentada no Conselho da Junta Real dos Diamantes, integrada pelo próprio intendente, que a presidia, e formada por mais 4 integrantes: o fiscal dos diamantes, os dois tesoureiros e o primeiro guarda-livros. A este se somava o secretário, que participava das sessões, mas não tinha direito a voto.

Após a descrição e a análise da estrutura de gestão, decisão e controle, Saint-Hilaire se dedica à operação propriamente dita, ou seja, os sítios de extração de pedras.

\subsection{A Operação dos Sítios de Extração dos Diamantes}

Inicialmente, é necessário nos familiarizarmos com alguns termos usados por Saint-Hilaire, como tropa e serviço. O autor explica que uma tropa consistia no agrupamento de pessoas sob o comando de cada administrador - em 1817, eram 8 tropas em funcionamento. Já serviço era como se denominavam os locais nos quais os diamantes eram extraídos, portanto uma tropa poderia estar geograficamente dividida em mais de um serviço. No entanto, para minimizar roubos, os administradores ordenavam contínuo movimento das tropas entre os diferentes serviços, de modo que os escravos não tivessem como esconder diamantes para posterior retirada dos locais de extração.

Em 1817, a produção já não atingia os picos registrados no século anterior e a administração estava endividada, por isso o valor do "aluguel" semanal de cada escravo havia baixado para \$675 e, posteriormente, cairia para $\$ 600$ (Saint-Hilaire, 1974).

A título de comparação, cerca de 30 anos antes, quando a estrutura fora implantada sob a égide das reformas pombalinas, o valor do aluguel de 1 cativo atingiu $1 \$ 200$.

Em 1817, Saint-Hilaire afirmou que havia por volta de mil escravos atuando nos diamantes, mas ele fora informado de que esse número, no fim do século anterior, havia chegado a 3 mil. Portanto, pode-se concluir que apenas o gasto com o aluguel de escravos havia sido reduzido a 1/6 do despendido na época da implantação das reformas que foram consequência das políticas de Marquês de Pombal.

A estrutura da operação de extração, detalhada no Quadro 2, contava com 8 administradores (dirigentes), 1 cabeça (subadministrador) por serviço, 3 feitores por serviço (responsáveis por vigiar e castigar os escravos), 1 guarda-armazém (suprimentos e materiais), 1 moleiro (moía os grãos), carpinteiros, serralheiros, 1 capelão para cada par de tropas e dezenas de escravos. 


\section{QUADRO 2 ESTRUTURA DE OPERAÇÃO (EXTRAÇÃO) DO DISTRITO DOS DIAMANTES}

\begin{tabular}{|c|c|c|c|c|}
\hline N. & Nome & Função & Remuneração & Quantidade \\
\hline 1 & Administradores & $\begin{array}{l}\text { Dirige um agrupamento de pessoas denominado } \\
\text { "tropa". }\end{array}$ & $200 \$ 000$ & Oito (em 1817) \\
\hline 2 & Cabeças & $\begin{array}{c}\text { Subadministradores, encarregados da fiscalização dos } \\
\text { feitores. Podem substituir os administradores, caso } \\
\text { necessário. }\end{array}$ & $\mathrm{Nl}$ & Um por serviço \\
\hline 3 & Feitores & Vigiar e castigar os escravos, caso necessário. & $100 \$ 000$ & Três por serviço \\
\hline 4 & Guarda-armazém & Controlar suprimentos e materiais. & $100 \$ 000$ & Um \\
\hline 5 & Moleiro & Moagem de grãos e alimentação. & $100 \$ 000$ & Um \\
\hline 6 & Carpinteiro & Montar, desmontar e manter as estruturas. & $\mathrm{Nl}$ & $\mathrm{Nl}$ \\
\hline 7 & Serralheiro & Montar, desmontar e manter as estruturas. & $\mathrm{Nl}$ & $\mathrm{Nl}$ \\
\hline 8 & Capelão & Serviços religioso & $160 \$ 000$ & 1 para duas tropas \\
\hline 9 & Escravos & Trabalho de busca dos diamantes. & \$675/semana & "Vários" por serviços \\
\hline
\end{tabular}

NI: Não informado

Fonte: Baseado em Saint-Hilaire (1974).

Ao detalhar a operação dos sítios de extração dos diamantes, Saint-Hilaire faz um retrato preciso da sociedade brasileira da época. Fica evidente que a ascensão social no Brasil colonial não se limitava somente a acumular ouro e sesmarias.

O ouro, para o escravo, significava a possibilidade de obtenção da liberdade por meio da aquisição de uma carta de alforria. Quando isso ocorria, os negros egressos do cativeiro, bem como "pardos e mulatos livres" (Palacin, 1994), reproduziam mimeticamente o comportamento dos senhores brancos: buscavam comprar outros negros para o trabalho braçal e gozar da ociosidade. Esse era o processo de afirmação de ascensão social comum naquela época (Razente, 2016), apesar de a participação dos forros na propriedade de escravos ter sido bem modesta (Luna, 1982).

Saint-Hilaire (1974) afirma que tal prática era usual entre os habitantes do Arraial do Tijuco, pois, como o governo usava mão de obra escrava alugada, a ascensão social se dava por meio da "terceirização" da força de trabalho, isto é, a aquisição de cativos, que eram postos para trabalhar nas minas, resultando em lucros para seus senhores brancos e antigos escravos libertos (forros).

\subsection{A Gestão de Pessoas}

Com base nas informações sintetizadas nos Quadros 1 e 2, verifica-se a brutal concentração de poder e de remuneração. De fato, considerando a despesa mensal com um escravo na ordem de $2 \$ 700-4$ semanas de custos de aluguel - e assumindo um contingente à época de mil homens, constata-se 
que os gastos da coroa com o intendente-geral das minas equivaliam ao custo hipotético de mais de 1,3 mil escravos - considerando que o intendente recebesse, entre ordenado e despesas de viagens, 4 contos de réis mensalmente $=4.000 \$ 000$.

Essa comparação ainda é falaciosa, no entanto, porque tais receitas eram auferidas pelos seus donos, que deveriam vesti-los e tratá-los em caso de moléstias. Para estimar o custo com cada escravo, faz-se necessário comparar os preços dos gêneros alimentícios com a dotação recebida por cada um deles.

Conforme o texto, a cada semana, os negros recebiam para sua alimentação 1/4 de alqueire de fubá, uma quantidade de feijão e um pouco de sal, e a esses víveres se adicionava ainda um pedaço de fumo de rolo. Quando faltava, o feijão era substituído pela carne. Os negros comiam 3 vezes por dia e, por não disporem de muito tempo durante o dia, eram obrigados a cozinhar seus alimentos à noite, sendo que, não raramente, o único combustível de que dispunham para fazê-lo eram as ervas secas (Saint-Hilaire, 1974).

A interpretação desses relatos é dificultada pelo uso de diferentes unidades de medidas, como arrobas, alqueires, feixes, entre outras. Todavia, o pesquisador enfatiza que "os valores cobrados no Tijuco eram mais caros que em outras partes da província" (Saint-Hilaire, 1974). O Quadro 3 apresenta os valores de aquisição dos principais itens de consumo na região. Como o autor mencionou moedas distintas, os valores foram ajustados nas moedas brasileira e francesa, em valores da época.

Não há elementos para calcular o custo dos suprimentos de cada escravo, portanto estimamos como 1/5 do valor do aluguel, o que totalizaria um custo semanal de $\$ 800$ para cada. Ainda assim, a remuneração do intendente equivaleria à de cerca de 1,1 mil escravos.

\section{QUADRO 3 PREÇOS PRATICADOS NO TIJUCO EM SETEMBRO DE 1817}

\begin{tabular}{lcccc} 
& & \multicolumn{2}{c}{ Preço conforme o texto original } & \multicolumn{2}{c}{ Valor ajustado } \\
Item & Medida & Em moeda local & Em francos & em réis \\
\hline Farinha de mandioca & 1 alqueire & $\$ 750$ & 4,68 & $\$ 750$ \\
Milho & 1 alqueire & $\$ 600$ & 3,75 & $\$ 600$ \\
Arroz & 1 alqueire & $1 \$ 800$ & 11,24 & $1 \$ 800$ \\
Toucinho & 1 arroba & 8 patacas & 16,00 & $2 \$ 560$ \\
Feijão & 1 alqueire & $\$ 900$ & 5,62 & $\$ 900$ \\
Frango & 1 unidade & $\$ 150$ & 0,95 & $\$ 150$ \\
Lenha & 1 feixe pequeno & 1 vintém & 0,20 & $\$ 20$
\end{tabular}

Fonte: Adaptado de Saint-Hilaire (1974).

Com base nessas informações, podem-se estimar as despesas mensais de custeio de pessoal em 1817. Assume-se que i) o ordenado dos oficiais da administração é mais baixo que o do ouvidor e mais alto que o do tesoureiro, no valor de 1.000\$000; ii) havia pelo menos 2 guarda-livros; iii) os cabeças, analogamente, teriam ordenado intermediário entre os administradores e os feitores, assumindo-se $\$ 120$; e iv) cada serviço dispunha de 1 carpinteiro, 1 serralheiro, 1 moleiro (para moagem de grãos) e 1 guarda-armazém, todos com a mesma remuneração. 
Estrutura de governança (15 pessoas)

Operação de extração (60 pessoas)

Aluguel e suprimentos de mil escravos

Total estimado da operação
$14.320 \$ 000$

$7.400 \$ 000$

$8.000 \$ 000$

$29.720 \$ 000$

Ou seja, 30 contos de réis para manter a operação do distrito dos diamantes, cerca de 187,5 mil francos. Ressaltamos que esse valor não contempla os custos dos postos de vigilância e dos militares a serviço no distrito dos diamantes nem os custos do envio anual dos minerais para o Rio de Janeiro. Ainda que a operação não fosse deficitária, na época do relato seus ganhos eram reduzidos, posto que, no fim do século XVIII, já haviam sido empregados até 3 mil escravos, com custo semanal de $1 \$ 200$.

Mesmo com perdas de contrabandos estimadas em $50 \%$ da extração, os ganhos da coroa com as riquezas do Brasil - diamantes, ouro, algodão, açúcar - foram significativos, a ponto de inverter a balança de operações entre Portugal e Inglaterra. Toda essa riqueza foi gerada com trabalho escravo, que constituíam o núcleo operacional, enquanto aos portugueses eram reservadas as atividades de gestão e de controle das operações.

Todos lucravam, exceto os negros escravizados, aos quais era destinado todo o trabalho braçal em condições insalubres, sem tempo de descanso, sem alimentação adequada e submetidos a castigos e espancamentos.

\subsection{A Gestão da Extração}

Saint-Hilaire permaneceu por uma semana no serviço do Rio Pardo, quando acompanhou o trabalho de extração, a partir de 22 de setembro de 1817.

Para acessar os locais de extração era necessário cruzar os postos do regimento das minas, nos quais os viajantes eram inspecionados, a fim de impedir o contrabando. Saint-Hilaire adentrou o distrito graças a uma portaria da coroa, que lhe franqueava o acesso. Ele não descreve como obteve a portaria nem detalha se foi proibido de circular por todo o distrito, mas afirma que o intendente autorizava seus deslocamentos. No entanto, ressalta a polidez e a boa educação dos membros dos regimentos, "todo diferente desta rusticidade grosseira que caracteriza frequentemente o soldado europeu” (Saint-Hilaire, 1974).

À época, a produção em grande parte de rios e riachos já se encontrava esgotada, e os serviços se moviam aleatoriamente, sem planejamento prévio. A motivação era dupla. Além de buscar novos locais, visava impedir que os negros pudessem esconder alguma pedra para posterior recuperação, afinal o trabalho dos escravos era árduo, pois eram "obrigados a estar continuamente dentro da água" (Saint-Hilaire, 1974). Mais do que isso, como decorrência da alimentação com baixo teor nutritivo, quase sempre com alimentos frios e malcozidos, os escravos se tornavam "morosos e apáticos" (SaintHilaire, 1974, p. 16).

Além disso, os acidentes de trabalho eram comuns, causados por esmagamentos de pedras deslocadas, desmoronamentos ou mesmo afogamentos. Ainda assim, Saint-Hilaire afirma que os escravos preferiam o trabalho nas minas aos afazeres domésticos ou nas fazendas, pois na extração as regras eram padronizadas e, "desde que se adaptassem", não teriam o que temer. Com um tom irônico, asseverou: "Reunidos em grande número, esses infelizes se divertem em seus trabalhos" (Saint-Hilaire, 1974). 
Se, entretanto, recuperarmos as ponderações sobre como ascender socialmente no Brasil Império, fica evidente que a principal motivação era racional e jazia na política de premiação, a qual determinava que todo escravo que encontrasse um diamante com peso mínimo de uma oitava teria a compra dele custeada pela administração e seria premiado com roupas novas e, acima de tudo, uma carta de alforria, isto é, a liberdade. Caso encontrassem pedras menores, receberiam prêmios proporcionais.

Ao longo de 1816, foram alforriados por premiação 3 escravos em todo o distrito dos diamantes, num universo estimado de mil, o que reflete a rigidez da estrutura social local.

Saint-Hilaire também descreveu os procedimentos de recepção, avaliação, pesagem e guarda das pedras, com as respectivas aposições de assinaturas, rubricas, conferências, verificações sequenciais até serem colocadas em caixas. Anualmente, as pedras eram transportadas para a corte, com participação do regimento de cavalaria e passagem por Vila Rica (atual Ouro Preto), quando um general rubricaria as caixas, sem abri-las, permitindo à comitiva seguir para a capital.

Constata-se o excessivo controle desde a extração nos rios até a chegada dos diamantes ao Rio de Janeiro, que visavam dar à coroa a certeza da boa gestão do negócio.

\section{REFLEXÕES: BRASIL, UM MUSEU DE GRANDES NOVIDADES}

Neste trabalho, ao apontarmos as principais características de estrutura, gestão e operação do distrito dos diamantes, foi possível delinear um retrato da administração pública brasileira, na alvorada do Reino Unido de Portugal, Brasil e Algarves (1816 e 1817). Vivia-se o início da formação do Estado Nacional, iniciado com a chegada da Família Real, em 1808. Ainda que já existisse uma administração anterior durante 3 séculos de Brasil colonial, considera-se a constituição do Estado Nacional a partir de 1808, com a chegada do Príncipe Regente. Todo um aparato burocrático foi montado às pressas, possibilitando a transformação de "uma constelação caótica de organismos superpostos em um aparelho de Estado" (Costa, 2010).

$\mathrm{Na}$ época da visita de Saint-Hilaire, o Brasil havia recém-saído da fase colonial dos vice-reis, que exerciam uma administração desordenada, na qual se misturavam ordenamentos, encargos, atribuições, circunscrições, disposições e missões. Segundo Costa (2010), o Brasil tinha uma estrutura "que não obedecia a princípios uniformes de divisão do trabalho, simetria e hierarquia". Entre os órgãos setoriais, incluía-se a intendência dos diamantes. $\mathrm{O}$ relato apresenta um cunho descritivo e detalhista, mas se concentra nas operações de extração dos diamantes. Ainda assim, o viajante naturalista francês ignora em seus relatos esse Estado em formação. Podem-se inferir pelo menos duas linhas de posicionamento dele a esse respeito.

A primeira hipótese é que Saint-Hilaire teria optado por não desagradar às autoridades luso-brasileiras à época de sua viagem, escolhendo uma postura isenta, em termos de posicionamentos críticos ou políticos. Essa ideia não se sustenta pelo fato de que sua obra só começou a ser publicada 10 anos depois de seu regresso à França. No volume em análise, o capítulo final é dedicado a apresentar as "revoluções do Brasil até a abdicação do imperador D. Pedro" (Saint-Hilaire, 1974). Entre o regresso dele e a publicação, passaram-se o regresso de D. João VI, a independência, o governo de Dom Pedro, sua renúncia e a instituição da regência trina provisória.

A segunda hipótese está calcada nos conceitos do iluminismo francês, por parte de Saint-Hilaire, e também na tentativa de aproximação de Portugal com o campo científico europeu. Kury (2004) destaca que, desde 1780, a reduzida e limitada elite científica de Portugal começou a se aproximar 
dos centros de conhecimento da Europa, como uma das consequências das reformas pombalinas, notadamente França e Inglaterra.

Ainda que não caiba neste trabalho aprofundar o iluminismo francês, constata-se que a jornada de Saint-Hilaire apresentava elementos caros ao iluminismo, como a defesa da utilidade dos estudos da natureza, o "utilitarismo devoto" e a crença de que a solução dos problemas da humanidade partiria do estudo detalhado dos 3 reinos: animal, vegetal e mineral (Kury, 2004). Ou seja, é plausível que tenha ocorrido a junção de uma possível estratégia civilizadora e solucionadora de problemas a partir da natureza, de Saint-Hilaire com a percepção da importância, por parte da elite intelectual luso-brasileira, de uma aproximação com os saberes científicos além da península ibérica.

Essa seria, em síntese, a melhor hipótese para a justificativa de um relato descritivo, tímido em críticas ou reprovações a respeito dos aspectos formais e informais do distrito dos diamantes e da administração do Reino Unido. Ao mesmo tempo que os viajantes estrangeiros contribuíam para estudo, análise e disseminação de informações sobre a natureza e as características sociais do Brasil, havia o risco de uso dessas informações por parte dos reinos de Inglaterra, França e Espanha, os 3 temidos por Portugal como possíveis invasores de suas colônias (Alexandre, 1993).

Cabe relembrar que discurso do viajante expressa a visão de um francês, e, conforme Orlando (1990), condições de produção do texto moldam os múltiplos sentidos a ele associados. Saint-Hilaire e a academia francesa nunca foram inocentes. Sua expedição coletou mais de 30 mil espécimes do solo brasileiro, e ele descreveu minuciosamente as operações do Estado. Por outro lado, conclui o último capítulo da obra com um olhar de compromisso com o Brasil, no qual não se furtou a traçar uma analogia entre os destinos do recém-nascido Império com a idade do príncipe, então com 6 anos: "É uma criança que ainda une as províncias deste vasto império!" E conclui afirmando: "Sou ligado a eles pelas forças da simpatia e da gratidão, amo ao Brasil quase tanto quanto à minha pátria" (Saint-Hilaire, 1974).

Para Portugal, mesmo que Saint-Hilaire não tenha deixado explícito, o cenário era desolador. Uma administração colonial sem racionalidade, lenta, frágil, despótica e centralizadora recebeu a chegada de uma corte que escapara da iminente invasão francesa. Os diamantes retirados do Brasil, mesmo com todo o aparato de vigilância, eram objetos de furto, roubo, sonegação, desvios de toda sorte. Mesmo os minerais que chegavam legalmente a Lisboa eram exportados como pedra bruta, pois nem o negócio da lapidação era dominado. Vivia-se o fim de um ciclo de quase um século, no qual os custos de produção eram incompatíveis com as quantidades encontradas no distrito dos diamantes, e conseguia-se ter uma operação deficitária mesmo com o uso pleno e injustificado de trabalho escravo.

Por fim, entendemos que esta nossa pesquisa abre veredas para outros estudos da administração pública com base em relatos de viajantes estrangeiros e para pesquisas sobre trabalho escravo ou que evidenciem as relações e as dinâmicas de poder, enfatizando a dimensão política de tais diferenças em termos ideológicos, sócio-históricos e culturais, bem como para trabalhos com foco nas políticas de divulgação, promoção e gestão da igualdade social.

A agenda de pesquisa também deve incluir estudos sobre a mudança da administração pública brasileira no período, incluindo os fatores econômicos, políticos e sociais associados à evolução do Estado brasileiro. 


\section{REFERÊNCIAS}

Alexandre, M. V. (1993). Os sentidos do Império: questão nacional e questão colonial na crise do Antigo Regime português. Porto, Lisboa: Afrontamento.

Amorim-Neto, O., \& Rodriguez, J. (2016). The new comparative-historical method and its contributions to political science and public administration. Revista de Administração Pública, 50(6), 1003-1026.

Barros, A. (2016). Archives and the "Archive": dialogue and an agenda of research in organization studies. Organizações \& Sociedade, 23(79), 609-623.

Barros, A., \& Carrieri, A. (2013). Ensino superior em administração entre os anos 1940 e 1950: uma discussão a partir dos acordos de cooperação Brasil-Estados Unidos. Cadernos EBAPE.BR, 11(2), 256-273.

Bertero, C., Barros, A., \& Alcadipani, R. (2018). Missionários americanos na Bahia: o bacharelado em administração da Escola de Administração da UFBA. Cadernos EBAPE.BR, 17(1), 144-155.

Bresser-Pereira, L. (2001). Do Estado patrimonial ao gerencial. In W. Pinheiro (Org.), Brasil: um século de transformações. São Paulo, SP: Companhia das Letras.

Cabral, D. (2011) Fontes para uma história políticoinstitucional: a experiência do Arquivo Nacional e a memória da administração pública brasileira. In Anais do $36^{\circ}$ Simpósio Nacional de História, São Paulo, SP.

Cabral, D., \& Camargo, A. (2010). Estado e administração: a corte joanina no Brasil. Rio de Janeiro, RJ: Arquivo Nacional.

Carvalho, L. (2003). Os pressupostos ideológicos das reformas pombalinas do estado português (17501777) (Dissertação de Mestrado). Universidade Federal de Goiás, Goiânia, GO.

Colomby, R., Peres, A., Lopes, F., \& Costa, S. (2016). A pesquisa em história de vida nos estudos organizacionais: um estudo bibliométrico. Farol - Revista de Estudos Organizacionais e Sociedade, 3(8), 852-887.

Coraiola, D. (2012). Importância dos arquivos empresariais para a pesquisa histórica em administração no Brasil. Cadernos EBAPE.BR, 10(2), 254-269.
Costa, A., Barros, D., \& Martins, P. (2010). Perspectiva histórica em administração: novos objetos, novos problemas, novas abordagens. Revista de Administração de Empresas, 50(3), 288-299.

Costa, A., \& Silva, M. (2019). A pesquisa histórica em administração: uma proposta para práticas de pesquisa. Administração - Ensino e Pesquisa, 20(1), 90-121.

Costa, F. L., \& Costa, E. (2010). Brasil: 200 anos de Estado, 200 anos de administração pública, 200 anos de reformas. Revista de Administração Pública, 42(5), 829-874.

Costa, F. L., \& Costa, E. (2016). Nova história da administração pública brasileira: pressupostos teóricos e fontes alternativas. Revista de Administração Pública, 50(2), 215-236.

Costa, F. L., \& Costa, E. (2018). História e representações da administração púbica brasileira. In Anais do $42^{\circ}$ Encontro da Anpad, Curitiba, PR.

Costa, I., \& Marcondes, R. (2016). A moeda no Brasil. Recuperado de http://ipeadata.gov.br/doc/ Moeda\%20no\%20Brasil\%20Colonia\%20e\%20 Imp\%C3\%A9rio.pdf

Couto, J. (2010). Rio de Janeiro: capital do Império Português (1808-1821). Lisboa, Portugal: Tribuna da História.

Curado, I. (2001). Pesquisa historiográfica em administração: uma proposta mercadológica. In Anais do $35^{\circ}$ Encontro da Anpad, Campinas, SP.

Joaquim, N., \& Carrieri, A. (2018). Construção e desenvolvimento de um projeto de história oral em estudos sobre gestão. Organizações \& Sociedade, 25(85), 303-319.

Kuri, L. (2003). Auguste de Saint-Hilaire, viajante exemplar. Intellèctus, 2(1), 1-11.

Kuri, L. (2004). Homens de ciência no Brasil: impérios coloniais e circulação de informações (1780-1810). História, Ciências, Saúde-Manguinhos, 11(suplemento1), 109-129.

Luna, F. (1982). Profissões, atividades produtivas e posse de escravos em Vila Rica ao alvorecer do século XVIII. In I. Costa (Ed.), Minas colonial: economia e sociedade. São Paulo, SP: Fipe/Pioneira.

Orlandi, E. (1990). Terra à vista! Velho e Novo Mundo. São Paulo, SP: Cortez. 
Palacin, L., \& Moraes, M. (1994). História de Goiás. Goiânia, GO: Editora UCG.

Rabello, D. (1997). Os diamantes do Brasil na regência de Dom João VI: um estudo de dependência externa. São Paulo, SP: Arte \& Ciência.

Razente, N. (2016). Povoações abandonadas no Brasil. Londrina, PR: Eduel.

Ribeiro, F. (2009). O passado colonial visto pelo Dasp: a história administrativa do Brasil. In Anais do $35^{\circ}$ Simpósio Nacional de História, São Paulo, SP.

Roncaglio, C. (2012). A história administrativa serve como subsídio para a organização da informação arquivística ou vice-versa? Revista Acervo, 25(2), 92-103.

Russel-Wood, A. (1998). Governantes e agentes. In F. Bethencourt, \& K. Chaudhuri (Orgs.), História da expansão portuguesa: o Brasil na balança do Império (1697-1808). Lisboa, Portugal: Círculo de Leitores.

Saint-Hilaire, A. (1974). Viagem pelo distrito dos diamantes e litoral do Brasil. São Paulo, SP: Edusp.

Samara, E., \& Silveira, I. (2017). História \& documento e metodologia de pesquisa. Belo Horizonte, $\mathrm{BH}$ : Autêntica.
Sodré, M. (2010). As viagens de Auguste SaintHilaire (bibliografia). In Biblioteca Nacional da França, \& Biblioteca Nacional do Brasil (Org.), A França no Brasil. Rio de Janeiro, RJ: BN Digital.

Svizzero, D. (2006). As múltiplas facetas do diamante. Revista USP, 71, 52-69.

Vizeu, F. (2018). Idort e difusão do management no Brasil na década de 1930. Revista de Administração de Empresas, 58(2), 163-173.

Wanderley, S. (2015). Desenvolviment(ism)o, descolonialidade e a geo-história da administração no Brasil: a atuação da Cepal e do Iseb como instituições de ensino e pesquisa em nível de pós-graduação (Tese de Doutorado). Fundação Getulio Vargas, Rio de Janeiro, RJ.

Wanderley, S. (2016). Iseb, uma escola de governo: desenvolvimentismo e a formação de técnicos e dirigentes. Revista de Administração Pública, 50(6), 913-936.

Wehling, A. (1986). Administração portuguesa no Brasil de Pombal a D. João (1777-1808). Rio de Janeiro, RJ: Fundação Centro de Formação de Servidor Público.

\section{Marcos Lopez Rego}

https://orcid.org/0000-0003-4743-4423

Doutor em Administração de Empresas pela Pontifícia Universidade Católica do Rio de Janeiro (PUC-Rio); Professor do IAG - A Escola de Negócios da PUC-Rio. E-mail: marcos@iag.puc-rio.br

\section{Hélio Reis Arthur Irigaray}

https://orcid.org/0000-0001-9580-7859

Doutor em Administração de Empresas pela FGV EAESP (2008); Professor da Escola Brasileira de Administração Pública e de Empresas da Fundação Getulio Vargas (FGV EBAPE). E-mail: helio.irigaray@fgv.br 